\title{
Mutagenicity of para-substituted $\alpha$-methylstyrene oxide derivatives with Salmonella
}

\author{
L.B. Rosman, V.G. Beylin, V. Gaddamidi, B.H. Hooberman and J.E. Sinsheimer * \\ College of Pharmacy, University of Michigan, Ann Arbor, MI 48109-1065 (U.S.A.)
}

(Received 26 September 1985)

(Revision received 3 February 1986)

(Accepted 7 March 1986)

\section{Summary}

A series of 5 para-substituted $\alpha$-methylstyrene oxide derivatives have been synthesized and together with $\alpha$-methylstyrene oxide as well as styrene oxide have been studied as to their mutagenicity with the TA100 and TA1535 strains of Salmonella typhimurium. A multiple regression analysis model has been developed which describes the mutagenicity of the $\alpha$-methylstyrene oxides in TA100. An increase in van der Waals volume was the most important variable in the model with greater improvement occurring with inclusion of the Hammett values for the para substituents on the compounds. The $\alpha$-methylstyrene oxides were less active alkylating agents with 4-( $p$-nitrobenzyl)pyridine than styrene oxide and with pyridine all reactivity was at the $\beta$-epoxide carbon. However all the $\alpha$-methylstyrene oxide derivatives, except for the bromo compound where toxicity was evident, showed mutagenicity values either greater or comparable to that of styrene oxide. These studies would indicate that reactivity at the $\beta$-carbon should also be a factor in describing the mutagenicity of the parent styrene oxide series.

In an extension of our studies on structure-mutagenicity relationships of aliphatic epoxides (Wade et al., 1978; Frantz and Sinsheimer, 1981; Neau et al., 1982), we have prepared a series of para-substituted $\alpha$-methylstyrene oxide derivatives,<smiles>[R]c1ccc(C2(C)CO2)cc1</smiles>

(where $\mathrm{R}=\mathrm{H}$, phenyl, $\mathrm{Cl}, \mathrm{Br}, \mathrm{CN}$ or $\mathrm{NO}_{2}$ )

and compared their mutagenicities in the Ames liquid preincubation procedure (Maron and Ames, 1983) with Salmonella strains TA100 and TA1535. Sugiura et al. (1978a,b, 1981) and Tamura et al.

\footnotetext{
* To whom correspondence should be addressed.
}

(1982) have developed structure- mutagenicity relationships for styrene oxide derivatives with various substituents on the phenyl group but have not examined the effect of further substituents on the epoxide ring. Sugiura et al. (1978a) reported that the mutagenicity of their compounds depended only on the reactivity at the benzylic, $\alpha(\mathrm{CH})$ epoxide carbon site and that reactivity at the $\beta\left(\mathrm{CH}_{2}\right)$ site as well as the partition coefficients of their epoxides appeared to have no effect. Tamura et al. (1982) in an extended series of styrene oxide compounds, confirmed that the electrophilic reaction of the $\alpha-\mathrm{CH}$ carbon, as indicated by Hammett's $\sigma$ values (McDaniel and Brown, 1958) for electronic effects of their para-styrene substituents, was a factor in the relative mutagenicities of their compounds. However, they also as- 


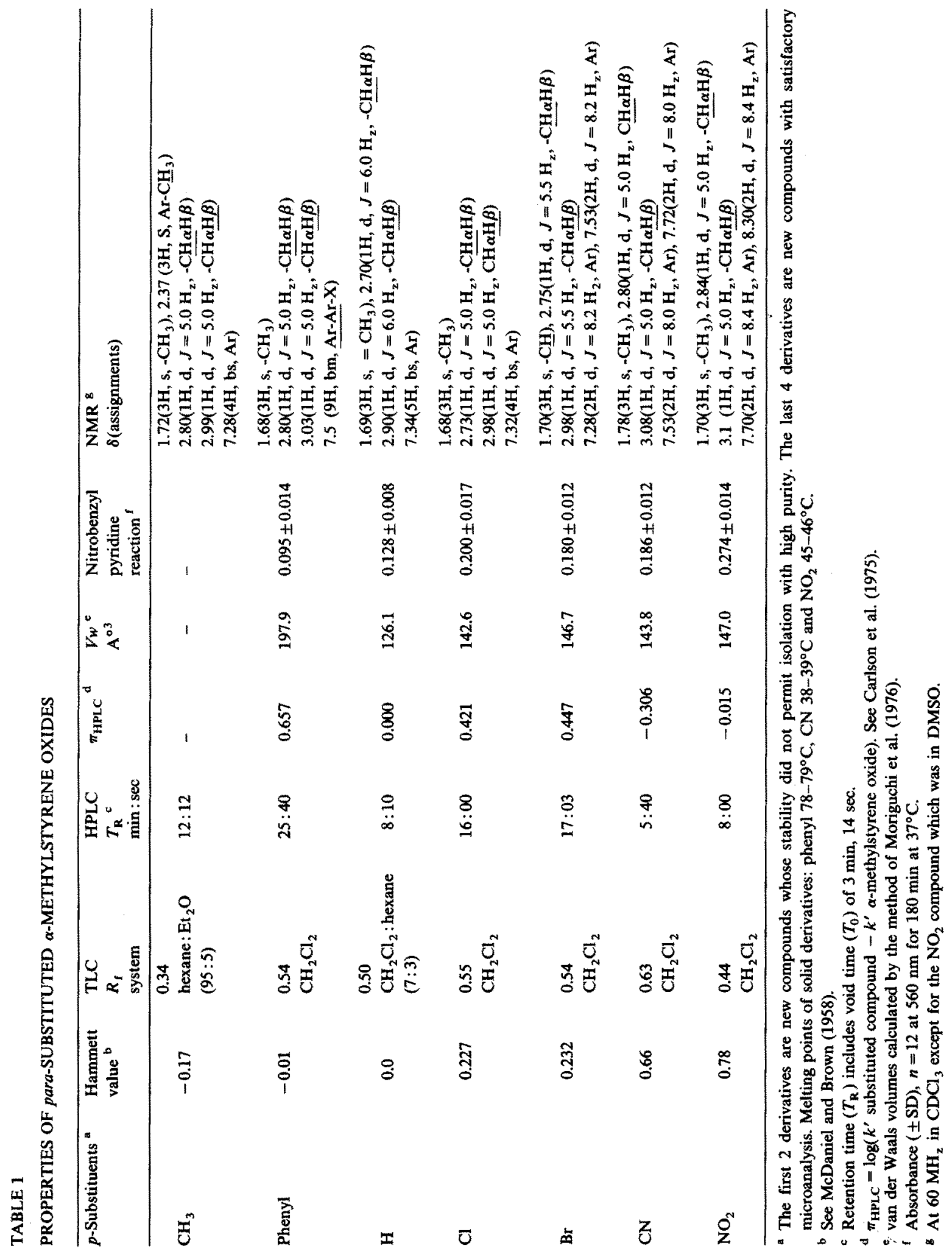


signed important roles to molecular volume and hydrophobicity.

Parker and Isaacs (1959), in reviewing the literature for the position of attack of epoxide carbons by nucleophilic reagents, noted that while the conjugative effect in compounds such as styrene oxide is of primary importance in explaining an increase in the rate of reaction at the $\alpha$ carbon, there is also an opposing steric effect with such substitution on the $\alpha$ carbon. Therefore, it was of interest to compare the relative mutagenicities of a series of $\alpha$-methylstyrene oxides where disubstitution on the $\alpha$ carbon would increase this steric effect. It was expected that disubstitution on the $\alpha$ carbon would increase nucleophilic attack at the $\mathrm{CH}_{2}$ carbon of the epoxides. Thus, the effect of such substitution would be on reactivity between the $\alpha$ and $\beta$ sites without major effect on the relative influence of electrophilicity, molecular volume or hydrophilicity, the factors used in the styrene oxide study of Tamura et al. (1982).

\section{Materials and methods}

\section{Test compounds}

Styrene oxide (Aldrich Chemical Company, Milwaukee, WI) was purified by distillation while $\alpha$-methylstyrene oxide (Chemtech Research Inc., Hayward, CA) was chromatographed twice over neutral alumina with hexane as the solvent.

The other $\alpha$-methylstyrene oxides in Table 1 were synthesized from their corresponding phenyl methyl ketones (Aldrich) by application of the methylene insertion reaction (Corey and Chaykovsky, 1965; Vig et al., 1977). Except for the paraphenyl compound, purification was possible by chromatography over neutral alumina (150 mesh, grade 1 , Aldrich) in which $1 \mathrm{~g}$ of the reaction mixtures were applied to a gravity column of $30 \mathrm{~g}$ alumina (deactivated to grade III with $1.2 \mathrm{ml}$ $\mathrm{H}_{2} \mathrm{O}$ ) and $\mathrm{CH}_{2} \mathrm{Cl}_{2}$-hexane $(8: 2)$ was the eluting solvent.

\section{Chromatography}

High-performance liquid chromatography (HPLC) was used to determine partition coefficients (Sugiura et al., 1978a) and to examine the purity of test compounds. The HPLC system consisted of Altex (Berkeley, CA) models 110A pump and 153 fixed-wavelength $(254 \mathrm{~nm})$ detector, Rheodyne (Berkeley, CA) model 7125 injector (20 $\mu 1$ ) and Whatman (Clifton, NJ) Partisil PXS 10/25 ODS -3 column preceded by a guard column $(50 \times$ 4.6 mm I.D.) packed with Whatman Co. Pell ODS 30-38 $\mu \mathrm{m}$ pellicular material. The mobile phase was methanol-water $(6: 4)$ at a flow rate of 1 $\mathrm{ml} / \mathrm{min}$.

Thin-layer chromatography (TLC) was used to monitor reactions, to determine $R_{\mathrm{f}}$ values and to examine the purity of test compounds. Analtech (Newark, DE) prescored silica-GF Uniplates $(2 \times$ $10 \mathrm{~cm}, 250 \mu$ ) and the solvent systems listed in Table 1 were employed. A compound was considered suitable for mutagenicity testing when a sample ( $2 \mu 1,10 \%$ solution) after development showed only one homogenous spot under UV observation and after alkylation of 4-( $p$-nitrobenzyl)pyridine (Hammock et al., 1974).

\section{Alkylating reactions of epoxides}

Rates of alkylation of the $\alpha$-methylstyrene oxides were compared by reaction at equimolar concentrations at $37^{\circ} \mathrm{C}$ for $180 \mathrm{~min}$ with $4-(p$ nitrobenzyl)pyridine as previously described (Hemminki, 1979; Nelis et al., 1982).

The effect of the addition of $\alpha$-methyl substitution on the position of epoxide-carbon attack by a nucleophile was studied by the method used by Sugiura et al. (1981) for their styrene oxide series. The reaction time was $18 \mathrm{~h}$ for all our compounds and NMR spectra of the reaction mixtures were recorded with sodium 2,2-dimethyl-2-silapentane5-sulfonate as the internal standard on a Varian (Palo Alto, CA) EM-360 spectrometer (60 MHz).

\section{Mutagénicity assay}

Mutagenicity testing using strains TA100 and TA1535 employed the preincubation assay outlined by Maron and Ames (1983) with the following specifications. To $0.5 \mathrm{ml}$ of $0.1 \mathrm{M}$ phosphate buffer ( $\mathrm{pH} 7.4$ ) was added $1.5 \mathrm{ml}$ of bacterial culture and $0.1 \mathrm{ml}$ of the epoxide in DMSO. These $3.5-\mathrm{ml}$ capped tubes were placed in a $37^{\circ} \mathrm{C}$ water bath for $1 \mathrm{~h}$ and then centrifuged at $9000 \mathrm{~g}$ for $10 \mathrm{~min}$ at $4^{\circ} \mathrm{C}$. The bacterial pellet was resuspended in $0.62 \mathrm{ml}$ of phosphate buffer. Three $0.2-\mathrm{ml}$ aliquots of the bacterial suspension were then pipetted into $2 \mathrm{ml}$ of histidine-biotin supple- 
mented top agar, vortexed and poured onto $100 \times$ $15 \mathrm{~mm}$ minimal agar plates. Glycidol was the positive control (1.0 $\mu$ mole/tube).

For single-dose testing, all compounds were assayed on the same day for mutagenicity and cytotoxicity with the mutagenicity protocol as outlined above. The following modifications of the procedure permitted examination for toxicity. The bacterial pellet was resuspended in $0.72 \mathrm{ml}$ of phosphate buffer solution. Three $0.2-\mathrm{ml}$ aliquots were added to $2 \mathrm{ml}$ of histidine-biotin supplemented top agar and poured onto histidine-biotin plates for mutagenicity testing. The remaining 0.1 $\mathrm{ml}$ was serially diluted $10^{5}$ in Oxoid broth, and $0.2 \mathrm{ml}$ of this mixture was incorporated with $2 \mathrm{ml}$ top agar onto histidine-biotin plates as a measure of surviving cells. These values were compared to the surviving cells from the DMSO control tests where the bacterial pellet was obtained and processed in the same manner.

\section{Results and discussion}

Except for $\alpha$-methylstyrene oxide, which is commercially available, the compounds of interest were synthesized by the methylene insertion method of Corey and Chaykovsky (1965) as modified by Vig et al. (1977). The physical-chemical properties for these new compounds are given in Table 1. Purification of these compounds required mild conditions because of the facile rearrangement of $\alpha$-methyl aryl oxiranes to carbonyl compounds (Banks and Ziffer, 1982) which is exemplified by those compounds bearing electrondonating substituents. However, it is unlikely that such carbonyl compounds contributed to the mutagenicity of the parent oxiranes of this study as no mutagenicity could be established for 2phenylpropionaldehyde (Aldrich) under our test conditions. Moreover, chromatography on deactivated neutralized alumina (Vig et al., 1977) produced, for most of the $\alpha$-methyl epoxide derivatives, compounds of high purity as indicated by their spectral characteristics as well as by their homogeneity on the HPLC and TLC systems described in the experimental section. However, in the case of $p$-phenyl- $\alpha$-methylstyrene oxide, chromatography and attempted distillation actually promoted decomposition. Therefore, the material isolated directly from the reaction mixture (greater than $90 \%$ pure by HPLC) was used without further purification for mutagenicity testing. The para-methyl derivative with its increased electrondonating character was less satisfactory in regard to its purity and was not suitable for mutagenicity testing.

The rates of alkylation for the $\alpha$-methylstyrene oxides with 4-( $p$-nitrobenzyl)pyridine are summarized in Table 1. In general, there is a strong positive correlation between alkylation rates and Hammett $\sigma$ values of the para substituents. This correlation improves from $r=0.84$ to $r=0.93$ when the cyano compound is excluded from the comparison. However, none of these $\alpha$-methyl compounds are as strong an alkylating agent as is styrene oxide with 4-( $p$-nitrobenzyl)pyridine. For example, in the direct comparison of p-nitro- $\alpha$ methylstyrene oxide with styrene oxide, the latter compound is over twice as effective as an alkylating agent (with an absorbance of $0.191 \pm 0.015$ vs. $0.082 \pm 0.011$ at $60 \mathrm{~min}$ ).

The position of nucleophilic attack of pyridine on the epoxide ring of the $\alpha$-methylstyrene oxides was determined by the NMR method of Tamura et al. (1982) in which the products
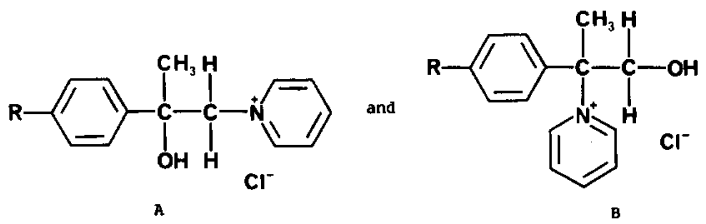

could be formed. In contrast to the styrene oxide series only product $A$ could be detected on the basis of methylene protons at $\delta 4.9$ to 5.0 and not at $\delta 4.4$ to 4.6 . Thus, all the alkylation occurs at the less hindered $\beta$-carbon and the effect of the para substituent on the distribution between $\alpha$ and $\beta$-carbon products as noted in the styrene oxide series is eliminated.

Mutagenicity testing with the TA100 and TA1535 strains of Salmonella typhimurium was performed in the liquid preincubation version of the Ames procedure as has been reported (Sugiura et al., 1978a, 1981; Tamura et al., 1982) for the mutagenicity testing of the parent styrene oxide series. The TA100 results for our $\alpha$-methyl series are given in Table 2 and the dose-response curves 
expressed in mean number of revertants are compared in Fig. 1. These same compounds were marginally active in TA1535 with little discernible differences in activity within the series.

As the dose-response data in Table 2 indicated that there was appreciable mutagenicity with TA100 at $0.5 \mu$ moles per tube for the majority of compounds but with limited toxicity, this level was selected for further study. Three measurements for each compound were made on the same day, under the same conditions and from the same initial inoculum. This approach was used to meet the conclusions reached by Salmeen and Durisin (1981) that the factors affecting growth rates of bacteria across experiments must be brought under practical control to obtain reproducibility in the Ames test. The relative mutagenicity values for the series of compounds obtained in this manner was confirmed on a second day. In addition, on both days relative toxicity data was estimated at $0.5 \mu$ mole per tube on histidine-biotin plates and are reported together with the mutagenicity results in Table 3. These data indicated toxicity to be a factor at the $0.5-\mu$ mole level for the nitro, bromo and phenyl derivatives. Toxicity was also noted for the bromo and phenyl derivatives at this level and for the other compounds at higher levels through a typical reduction in background lawn. There was no demonstrable mutagenicity for the para-bromo derivative at any dose.

Tamura et al. (1982) examined the parent styrene oxide series for correlations of relative

TABLE 2

DOSE-MUTAGENICITY RESPONSE RESULTS IN SALMONELLA TA100 LIQUID PREINCUBATION TEST

\begin{tabular}{|c|c|c|c|c|c|c|c|c|c|}
\hline \multirow[t]{2}{*}{$\begin{array}{l}\text { Compound } \\
\text { Substituent }\end{array}$} & \multicolumn{9}{|c|}{$\begin{array}{l}\text { Revertants }{ }^{\mathrm{a}} \\
\text { dose ( } \mu \text { moles/preincubation tube) }\end{array}$} \\
\hline & $0^{b}$ & 0.01 & 0.1 & 0.5 & 1 & 2.5 & 5 & 10 & 10 \\
\hline \multicolumn{10}{|c|}{$\alpha$-Methylstyrene oxides } \\
\hline $\mathrm{H}$ & $\begin{array}{l}106 \pm 19 \\
156 \pm 13 \\
147 \pm 13\end{array}$ & $\begin{array}{l}131 \pm 8 \\
152 \pm 8\end{array}$ & $\begin{array}{l}150 \pm 14 \\
203 \pm 14\end{array}$ & $499 \pm 22$ & $\begin{array}{l}665 \pm 42 \\
824 \pm 43\end{array}$ & $2492 \pm 565$ & $3355 \pm 13$ & $\begin{array}{l}3435 \pm \\
3604 \pm 10\end{array}$ & $\begin{array}{r}92^{c} \\
019^{c}\end{array}$ \\
\hline $\mathrm{Br}$ & $\begin{array}{l}120 \pm 3 \\
110 \pm 17 \\
147 \pm 13\end{array}$ & $\begin{array}{l}121 \pm 12 \\
121 \pm 10\end{array}$ & $\begin{array}{l}110 \pm 14 \\
116 \pm 16\end{array}$ & $125 \pm 14$ & $\begin{array}{l}83 \pm 9^{c} \\
67 \pm\end{array}$ & $97 \pm 14^{c}$ & $72 \pm 8^{c}$ & $\begin{array}{l}58 \pm \\
48 \pm\end{array}$ & $\begin{array}{r}13^{c} \\
4^{c}\end{array}$ \\
\hline $\mathrm{Cl}$ & $\begin{array}{r}99 \pm 10 \\
110 \pm 17 \\
147 \pm 13\end{array}$ & $\begin{array}{l}117 \pm 4 \\
119 \pm 17\end{array}$ & $\begin{array}{l}138 \pm 22 \\
120 \pm 19\end{array}$ & $339 \pm 29$ & $\begin{array}{l}362 \pm 94 \\
341 \pm 53\end{array}$ & $437 \pm 40$ & $92 \pm 12^{c}$ & $\begin{array}{l}42 \pm \\
73 \pm\end{array}$ & $\begin{array}{r}20^{c} \\
5^{c}\end{array}$ \\
\hline $\mathrm{CN}$ & $\begin{array}{l}106 \pm 11 \\
114 \pm 4 \\
147 \pm 13\end{array}$ & $\begin{array}{l}107 \pm 11 \\
115 \pm 9\end{array}$ & $\begin{array}{l}140 \pm 12 \\
111 \pm 11\end{array}$ & $209+8$ & $\begin{array}{l}212 \pm 17 \\
204 \pm 35\end{array}$ & $420 \pm 12$ & $707 \pm 104$ & $\begin{array}{l}795 \pm \\
922 \pm\end{array}$ & $\begin{array}{l}77 \\
92\end{array}$ \\
\hline $\mathrm{NO}_{2}$ & $\begin{array}{r}106 \pm 11 \\
97 \pm 6 \\
147 \pm 13\end{array}$ & $\begin{array}{l}128 \pm 12 \\
128 \pm 24\end{array}$ & $\begin{array}{l}230 \pm 36 \\
199 \pm 12\end{array}$ & $310 \pm 10$ & $\begin{array}{l}468 \pm 69 \\
345 \pm 50\end{array}$ & $627 \pm 44$ & $796 \pm 30$ & $\begin{array}{l}862 \pm 1 \\
650 \pm\end{array}$ & $\begin{aligned} 129^{c} \\
80^{c}\end{aligned}$ \\
\hline phenyl & $\begin{array}{r}82 \pm 10 \\
97 \pm 6 \\
147 \pm 13\end{array}$ & $\begin{array}{l}201 \pm 32 \\
234 \pm 64\end{array}$ & $\begin{array}{r}1119 \pm 227 \\
840 \pm 367\end{array}$ & $2273 \pm 171$ & $\begin{array}{r}600 \pm 344^{\mathrm{c}} \\
1257 \pm 162^{\mathrm{c}}\end{array}$ & $484 \pm 114^{c}$ & $165 \pm 64^{c}$ & $\begin{array}{l}2 \pm \\
1 \pm\end{array}$ & $\begin{array}{l}2^{c} \\
2^{c}\end{array}$ \\
\hline Styrene oxide & $\begin{array}{r}99 \pm 10 \\
114 \pm 4 \\
147 \pm 13 \\
\end{array}$ & $\begin{array}{l}120 \pm 2 \\
108 \pm 8\end{array}$ & $\begin{array}{l}130 \pm 11 \\
124 \pm 18\end{array}$ & $202 \pm 11$ & $\begin{array}{l}334 \pm 18 \\
327 \pm 60\end{array}$ & $676 \pm 91$ & $1389 \pm 349$ & $\begin{array}{r}917 \pm 2 \\
1406 \pm\end{array}$ & $\begin{array}{r}293^{c} \\
56\end{array}$ \\
\hline
\end{tabular}

a Mean revertants per plate \pm standard deviation, where $n=3$ per test.

b Bacteria is dissolved in $0.1 \mathrm{ml}$ of dimethyl sulfoxide for the negative control.

c A reduction in background lawn was observed. 


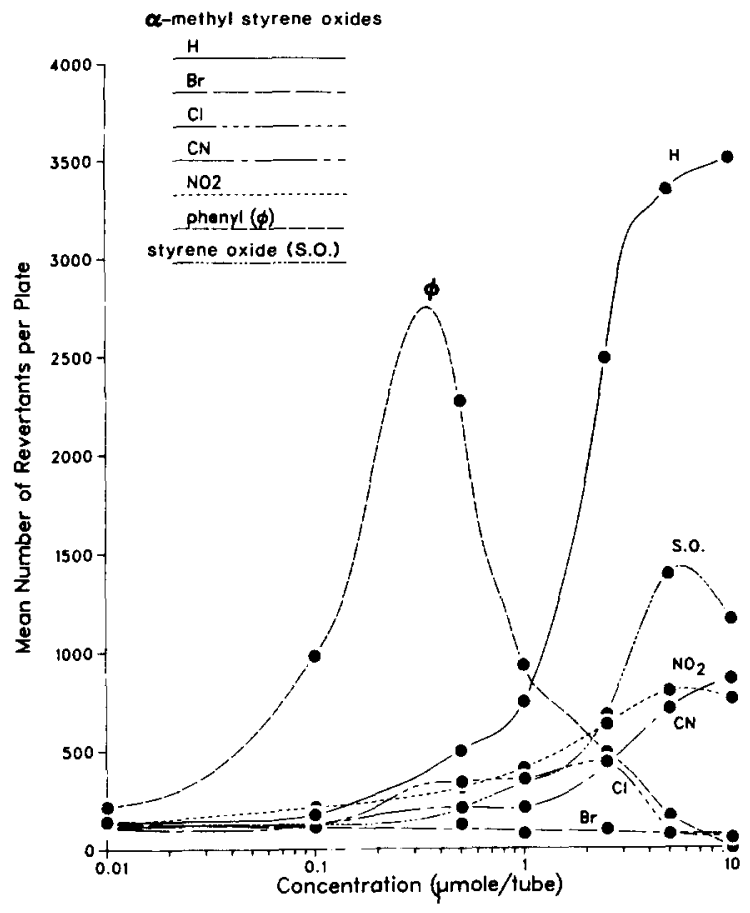

mutagenicity with Hammett values ( $\sigma$ ), van der Waals volumes $(V w)$ and partition values $\left(\pi_{\text {HPLC }}\right)$. We applied multiple regression analyses to mutagenicity determinations $(n=36)$ for the data set, where there were 6 measurements for each of the 6 $\alpha$-methylstyrene oxide compounds. In this analysis, mutagenicity is expressed as the induced mutant fraction (MF) as recently described by Thilly (1985) where $M F=$ [(revertants per plate for test compound - mean revertants for control) $\div$ mean surviving cells for test compound] (mean revertants for control $\div$ mean surviving cells for control). The results for the regression analysis are summarized in Table 4 . The inclusion of all 3 parameters (eqn. 7) resulted in the best model. As shown in eqn. $3, V w$ was the most important variable in the model with more improvement

Fig. 1. Dose-mutagenic response curves with TA100 for parasubstituted $\alpha$-methylstyrene oxides and styrene oxide in the liquid preincubation Ames test.

TABLE 3

MUTAGENICITY IN TA100 LIQUID PREINCUBATION TEST AT $0.5 \mu$ moles PER TUBE

\begin{tabular}{crrr}
\hline $\begin{array}{l}\text { Compound } \\
\text { Substituent }\end{array}$ & Revertants $^{\mathrm{a}}$ & $\begin{array}{l}\text { Surviving } \\
\text { cells }\left(\times 10^{6}\right)^{\mathrm{a}}\end{array}$ & $\begin{array}{l}\text { Induced } \\
\text { mutant fraction } \\
\left(\times 10^{-6}\right)^{\mathrm{a}, \mathrm{b}}\end{array}$ \\
\hline $\begin{array}{c}\alpha \text {-Methylstyrene oxides } \\
\mathrm{H}\end{array}$ & $554 \pm 16$ & $1625 \pm 43$ & $0.1686 \pm 0.0100$ \\
& $659 \pm 27$ & $1134 \pm 43$ & $0.1846 \pm 0.0238$ \\
$\mathrm{Br}$ & $87 \pm 19$ & $690 \pm 11$ & $-0.1470 \pm 0.0277$ \\
& $226 \pm 5$ & $1146 \pm 61$ & $-0.1976 \pm 0.0040$ \\
$\mathrm{Cl}$ & $320 \pm 15$ & $1453 \pm 128$ & $0.0390 \pm 0.0104$ \\
& $401 \pm 19$ & $1755 \pm 190$ & $-0.1008 \pm 0.0111$ \\
$\mathrm{CN}$ & $193 \pm 1$ & $1275 \pm 117$ & $0.0417 \pm 0.0009$ \\
& $312 \pm 25$ & $1594 \pm 158$ & $-0.1457 \pm 0.0157$ \\
$\mathrm{NO} \mathrm{C}_{2}$ & $247 \pm 6$ & $596 \pm 29$ & $0.1150 \pm 0.0092$ \\
& $419 \pm 38$ & $643 \pm 28$ & $0.1087 \pm 0.0593$ \\
phenyl & $1182 \pm 80$ & $373 \pm 49$ & $2.7476 \pm 0.2153$ \\
& $2655 \pm 287$ & $623 \pm 64$ & $3.7073 \pm 0.4604$ \\
Styrene oxide & $241 \pm 12$ & $1337 \pm 32$ & \\
& $345 \pm 14$ & $1366 \pm 119$ & \\
Control & $120 \pm 9$ & $1216 \pm 67$ & \\
& $217 \pm 4$ & $1056 \pm 66$ & \\
\hline
\end{tabular}

${ }^{a}$ Mean \pm standard deviation where $n=3$.

${ }^{b}$ Induced mutant fraction $=\left(R_{\mathrm{t}}-\bar{R}_{\mathrm{c}}\right) / \bar{S}_{\mathrm{t}}-\left(\bar{R}_{\mathrm{c}} / \bar{S}_{\mathrm{c}}\right)$, where: $R_{\mathrm{t}}=$ revertants per plate for test compound, $\bar{R}_{\mathrm{c}}=$ mean revertants for control, $\bar{S}_{\mathrm{t}}=$ mean surviving cells for test compound and $\bar{S}_{\mathrm{c}}=$ mean surviving cells for control. See Thilly (1985). 
TABLE 4

REGRESSION EQUATIONS OF INDUCED MUTANT FRACTION ( $M F$ ) AT $0.5 \mu$ mole/TUBE FOR $p$-SUBSTITUTED $\alpha$-METHYLSTYRENE OXIDES AS A FUNCTION OF HAMMETT VALUE (o), PARTITION COEFFICIENT ( $\left.\pi_{\text {HPLC }}\right)$ AND/OR MOLECULAR VOLUME $(V w)$

\begin{tabular}{|c|c|c|c|c|c|c|c|c|}
\hline \multirow[t]{2}{*}{ Equation } & \multicolumn{3}{|c|}{ Coefficients \pm standard error } & \multirow{2}{*}{$\begin{array}{l}\text { Constant } \\
\left(B_{0}\right)\end{array}$} & \multirow[t]{2}{*}{$R$} & \multirow[t]{2}{*}{$R^{2}$} & \multirow[t]{2}{*}{$\mathrm{SE}$} & \multirow{2}{*}{$\begin{array}{l}F \text { Test } \\
P\end{array}$} \\
\hline & $\bar{\sigma}$ & $\pi_{\text {HPLC }}$ & $V w$ & & & & & \\
\hline 1 & $-1.924 \pm 0.611$ & & & 1.142 & 0.4750 & 0.2257 & 1.1151 & 0.0034 \\
\hline 2 & & $3.283 \pm 0.714$ & & 0.039 & 0.6190 & 0.3831 & 0.9952 & 0.0001 \\
\hline 3 & & & $0.050 \pm 0.040$ & -7.019 & 0.9068 & 0.8223 & 0.5342 & $<0.0001$ \\
\hline 4 & $-0.416 \pm 0.749$ & $2.913 \pm 0.981$ & & 0.226 & 0.6236 & 0.3888 & 1.0055 & 0.0003 \\
\hline 5 & $-1.032 \pm 0.250$ & & $0.046 \pm 0.003$ & -6.137 & 0.9396 & 0.8828 & 0.4403 & $<0.0001$ \\
\hline 6 & & $0.031 \pm 0.530$ & $0.050 \pm 0.006$ & -6.991 & 0.9068 & 0.8223 & 0.5442 & $<0.0001$ \\
\hline 7 & $-2.030 \pm 0.257$ & $-2.434 \pm 0.442$ & $0.062 \pm 0.004$ & -7.514 & 0.9695 & 0.9398 & 0.3204 & $<0.0001$ \\
\hline
\end{tabular}

noted with the inclusion of Hammett values (eqn. 5) than with partition values (eqn. 6).

While caution should be used in predicting mutagenicity from such models due to the limited number of compounds involved and the problem of multicollinearity (Neter and Wasserman, 1974), our model is useful for comparison to the prior styrene oxide results. The relative importance of the independent variables in the present study are the same as those reported by Tamura et al. (1982) for the styrene oxide series. However, a logarithmic presentation of $V w$ as used by these investigators did not improve the fit of our data and there was no need to use a logarithmic transformation of the mutagenicity term. It is interesting that in our model we observe a negative correlation of Hammett values to induced mutant fraction. While a negative correlation is explained in the parent styrene oxide series on the basis of reactivity at the $\alpha$-carbon (Sugiura et al., 1978), this is not the case in the present series as established by reaction with the model nucleophile, pyridine. It is unfortunate that the lack of stability of $\alpha$-methylstyrene oxides with strong electron-donating groups in the para-position did not permit an extension of this series to obtain a further range of Hammett values for correlation studies.

From the dose-response data (Fig. 1 and Table 2) and the single dose results (Table 3 ) it is clear that $\alpha$-methylstyrene oxide and its para-phenyl derivative are the most mutagenic compounds in the present series and that they exhibited greater mutagenicity than styrene oxide on direct comparison. Indeed, all the $\alpha$-methylstyrene oxides, except for the bromo compound, showed mutagenicity values in Table 3 either greater than or comparable to that of styrene oxide. This is in spite of the fact that the chemical alkylation studies with pyridine indicated that the $\alpha$-methyl group was effective in shifting the site of reactivity for the epoxides from the $\alpha$ - to the $\beta$-carbon.

This comparatively high mutagenicity for the $\alpha$-methyl series raises the question of whether reactivity at the $\beta$-carbon should also be a factor in understanding the mutagenicity of the parent styrene oxide. Such reactivity and our regression analysis data are in contrast with the conclusion of Sugiura et al. (1978) that mutagenicities of the styrene oxides with Salmonella can be explained solely on the basis of the Hammett values of the para substituents with reactivity only at the benzylic $(\alpha)$ site. However, they are consistent with the more recent observations of Tamura et al. (1982) on their expanded series of styrene oxides that Hammett values alone do not describe the mutagenicities of styrene oxides.

\section{Acknowledgements}

The authors express their appreciation to Dr. Bruce Ames, University of California at Berkeley 
for supplying Salmonella TA100 and TA1535. This investigation was supported by Grant RO1 ES03345 from the National Institute of Environmental Health Sciences, DHHS.

\section{References}

Banks, H., and H. Ziffer (1982) Effect of ring size and methyl substituents on LiBr-catalyzed rearrangements of aryloxiranes, J. Org. Chem., 47, 3743-3747.

Carlson, R.M., R.E. Carlson and H.L. Kopperman (1975) Determination of partition coefficients by liquid chromatography, J. Chromatog., 107, 219-223.

Corey, E.J., and M. Chaykovsky (1965) Dimethyloxosulfonium methylide and dimethylsulfonium methylide formation and application to organic synthesis, J. Am. Chem. Soc., 87, 1353-1364.

Frantz, S.W., and J.E. Sinsheimer (1981) Bacterial mutagenicity and toxicity of cycloaliphatic epoxides, Mutation Res., 90, 67-78.

Hammock, L.G., B.D. Hammock and J.E. Casida (1974) Detection and analysis of epoxides with 4-( $p$-nitrobenzyl)pyridine, Bull. Environ. Contam. Toxicol., 12, 759-764.

Hemminki, K., and K. Falck (1979) Correlation of mutagenicity and 4-( $p$-nitrobenzyl)-pyridine alkylation by epoxides, Toxicol. Lett., 4, 103-106.

Maron, D.M., and B.N. Ames (1983) Revised methods for the Salmonella mutagenicity test, Mutation Res., 113, 173-215.

Moriguchi, I., Y. Kanada and K. Komatsu (1976) Van der Waals volume and the related parameters for hydrophobicity in structure-activity studies, Chem. Pharm. Bull., 24, 1799-1806.

McDaniel, D.H. and H.C. Brown (1958) An extended table of Hammett substituent constants based on the ionization of substituted benzoic acids, J. Org. Chem., 23, 420-427.

Neau, S.H., B.H. Hooberman, S.W. Frantz and J.E. Sinsheimer (1982) Substituent effects on the mutagenicity of phenyl glycidyl ethers in Salmonella typhimurium, Mutation Res., 93, 297-304.

Nelis, H.J.C.F., S.C. Airy and J.E. Sinsheimer (1982) Comparison of the alkylation of nicotinamide and 4-( $p$-nitrobenzyl)pyridine for the determination of aliphatic epoxides, Anal. Chem., 54, 213-216.

Neter, J., and W. Wasserman (1974) Applied Linear Statistical Models, Irwin, Homewood, IL, pp. 250-254, 341-344.

Parker, R.E., and N.S. Isaacs (1959) Mechanisms of epoxide reactions, Chem. Rev., 59, 737-799.

Salmeen, I., and A.M. Durisin (1981) Some effects of bacteria population on quantitation of Ames Salmonella-histidine reversion mutagenesis assays, Mutation Res., 85, 109-118.

Sugiura, K. and M. Goto (1981) Mutagenicities of styrene oxide derivatives on bacterial test systems: relationship between mutagenic potencies and chemical reactivity, Chem.-Biol. Interact., 35, 71-91.

Sugiura, K., T. Kimura and M. Goto (1978a) Mutagenicities of styrene oxide derivatives on Salmonella typhimurium (TA100), Relationship between mutagenic potencies and chemical reactivity, Mutation Res., 58, 159-165.

Sugiura, K., S. Yamanaka, S. Fukasawa and M. Goto (1978b) The mutagenicity of substituted and unsubstituted styrene oxides in $E$. coli: relationship between mutagenic potencies and physico-chemical properties, Chemosphere, 9, 737-742.

Tamura, N., K. Takahashi, N. Shirai and Y. Kawazoe (1982) Studies on chemical carcinogens, XXI. Quantitative structure-mutagenicity relationship among substituted styrene oxides, Chem. Pharm. Bull., 30, 1393-1400.

Thilly, W.G. (1985) Dead cells don't form mutant colonies: a serious source of bias in mutation assays, Environ. Mutagen., 7, 255-258.

Vig, O.P., S.S. Bari, S.D. Sharma and S.S. Rana (1977) Terpenoids: part CXXX, a new synthesis of dehydro- $\alpha$ curcumene, Indian J. Chem., 15B, 1076-1077.

Wade, D.R., S.C. Airy and J.E. Sinsheimer (1978) Mutagenicity of aliphatic epoxides, Mutation Res., 58, 217-223. 